УДК 69.058 .8

\title{
ОЦЕНКА СТЕПЕНИ ЖИВУЧЕСТИ ОТВЕТСТВЕННЫХ СТРОИТЕЛЬНЫХ КОНСТРУКЦИЙ ПРИ УДАРНО-ВОЛНОВОМ НАГРУЖЕНИИ
}

\author{
Однокопылов Георгий Иванович', \\ OGIz@yandex.ru
}

\author{
Саркисов Дмитрий Юрьевич², \\ Milandd@yandex.ru \\ Бутузов Егор Анатольевич², \\ egorko18m@gmail.com \\ Национальный исследовательский Томский политехнический университет, \\ Россия, 634050, г. Томск, пр. Ленина, 30. \\ 2 Томский государственный архитектурно-строительный университет, \\ Россия, 634003, г. Томск, пл. Соляная, 2.
}

\begin{abstract}
Актуальность работы обусловлена техническим усложнением объектов нефтегазового комплекса вследствие увеличения объемов и скорости добычи сырья, на которые возможно воздействие ударно-волновых нагрузок при нештатных ситуациях. Причинами воздействия могут быть взрывы, падения тяжелых грузов, террористические акты, природные и техногенные катастрофы и т. Д. Данные ситуации с большой вероятностью приводят к значительному повреждению строительных конструкций производственных зданий и сооружений. Вследствие чего для обеспечения дальнейшего функционирования сооружения необходимо проектировать строительные конструкции и объект в целом, обладающие свойствами живучести при нестационарном воздействии. Учет таких свойств должен анализироваться при построении сценариев возникновения и развития нештатных ситуаций, а также при анализе рисков. Таким образом, разработка способов оценки степени живучести строительных конструкций при ударно-волновом воздействии является актуальной задачей.

Цель работы: создание практически применимого способа оценки степени живучести строительной конструкции при кратковременном ударно-волновом нагружении на основе анализа энергетического параметра.

Методы исследования: измерения ускорений, прогибов и нагрузки методами тензометрии, графоаналитический метод исследования с применением программы Microsoft Excel.

Результаты. Разработан способ оценки степени живучести строительной конструкции при ударно-волновом нагружении для ответственных строительных конструкций сооружений нефтегазового комплекса с применением коэффициента степени живучести. На примере конкретного испытания изгибаемого железобетонного элемента на кратковременную динамическую нагрузку получены значения указанного коэффициента. Внесены предложения по направлениям использования коэффициента степени живучести при проектировании строительных конструкций зданий и сооружений, эксплуатируемых при возможном воздействии кратковременных динамических нагрузок.
\end{abstract}

\section{Ключевые слова:}

Степень живучести, энергия упругой деформации, работа, кратковременное динамическое нагружение, ударно-волновое нагружение, железобетон, экспериментальные исследования

\section{Актуальность исследования}

Согласно федеральному закону № 116-Ф3 «0 промышленной безопасности опасных производственных объектов», многие объекты нефтегазового комплекса относятся к категории опасных производственных объектов, например, цеха нефтеили газоперерабатывающих заводов, стационарные платформы и др.

На опасных производственных объектах всегда существует повышенная вероятность возникновения чрезвычайной ситуации аварийного характера, вследствие которой могут происходить взрывы и воздействия на строительные конструкции кратковременных динамических нагрузок. Такие нагрузки характеризуются резким нарастанием фронта, коротким сроком действия и волновым характером воздействия.

При строительстве указанных объектов для возведения несущих остовов зданий и сооружений часто используется монолитный или сборный железобетон.
Основным требованием, предъявляемым к несущим строительным конструкциям при аварийных воздействиях, является сохранение несущей способности, при этом прогибы и деформации в общем случае не нормируются, а, следовательно, в целях экономии при проектировании можно использовать все ресурсы пластической работы материала. По сути, конструкция должна обладать свойством живучести при воздействии на нее кратковременных динамических нагрузок. Применение методов теории живучести технических систем [1-7] и статических и динамических оценок функционирования технических объектов позволяет точнее определить остаточный ресурс строительных конструкций, а также зданий и сооружений после воздействий сверхнормативных динамических нагрузок.

Сложность процессов, происходящих в железобетоне при кратковременном динамическом воздействии [8-30], особенно в пластической стадии 
работы материала, делает неотъемлемой частью работы по проектированию таких конструкций экспериментальные исследования.

В то же время экспериментальные исследования имеют ограничения в плане наличия необходимого оборудования и методов его использования (возможность установки и применения, недопущения повреждений вследствие высокой стоимости, воспроизводимость полученных данных и др.).

Таким образом, перед исследователями стоит задача создавать доступные способы обработки и интерпретации информации, полученной при экспериментальных исследованиях, с возможностью их практического применения. Такие способы должны быть воспроизводимы и применимы при проведении испытаний конструкций с различными динамическими параметрами.

В работе предложена методика для оценки степени живучести ответственных строительных конструкций при ударно-волновом нагружении. В качестве примера рассмотрено испытание изгибаемого железобетонного элемента при действии кратковременной динамической нагрузки.

Целью работы является создание практически применимого способа оценки степени живучести строительной конструкции при кратковременном ударно-волновом нагружении на основе анализа энергетического параметра.

\section{Экспериментальные исследования}

Исследования работы изгибаемого железобетонного элемента проводились на действие ударной нагрузки на основе копровой установки. Опытный образец представлял собой железобетонную балку длиной 2,0 м, сечением 90*180 мм, армиро- ванную четырьмя стержнями продольной арматуры диаметром 10 мм класса А400. Условия закрепления образца - шарнирные, схема однопролетная, расчетный пролет составлял 1,8 м. Деформирование образца происходило путем передачи энергии падающего с высоты 0,5 м груза массой 430 кг. Модель и реализация стенда приведены на рис. 1.

Для контроля величины нагрузки при эксперименте был применен датчик силоизмерительный тензорезистивного типа ДСТ4126 с допускаемым усилием при статическом воздействии до $2000 \mathrm{kH}$ (при кратковременном динамическом нагружении до $200 \mathrm{\kappa H})$, контроль давлений осуществлялся месдозами - 2 шт. Датчик для измерения нагрузки от падающего груза устанавливался в середине пролета распределительной траверсы. Для достижения необходимого времени действия нагрузки на датчик сверху устанавливался комплект резиновых прокладок.

Для записи ускорений и прогибов в контрольных точках экспериментального образца (пять точек, равномерно распределенных по длине) устанавливались акселерометры ARF-10000A и прогибомеры WayCon RL150-G-SR. Используемые приборы и схемы их расстановки представлены на рис. $2,3$.

Для регистрации показаний всех датчиков в процессе эксперимента были применены сертифицированные измерительные системы MIC-300m и MIC-036r (рис. 4).

Все датчики были подсоединены через кабели, имеющие защиту от помех, чем достигалась необходимая точность при синхронизации показаний со всех датчиков во времени.

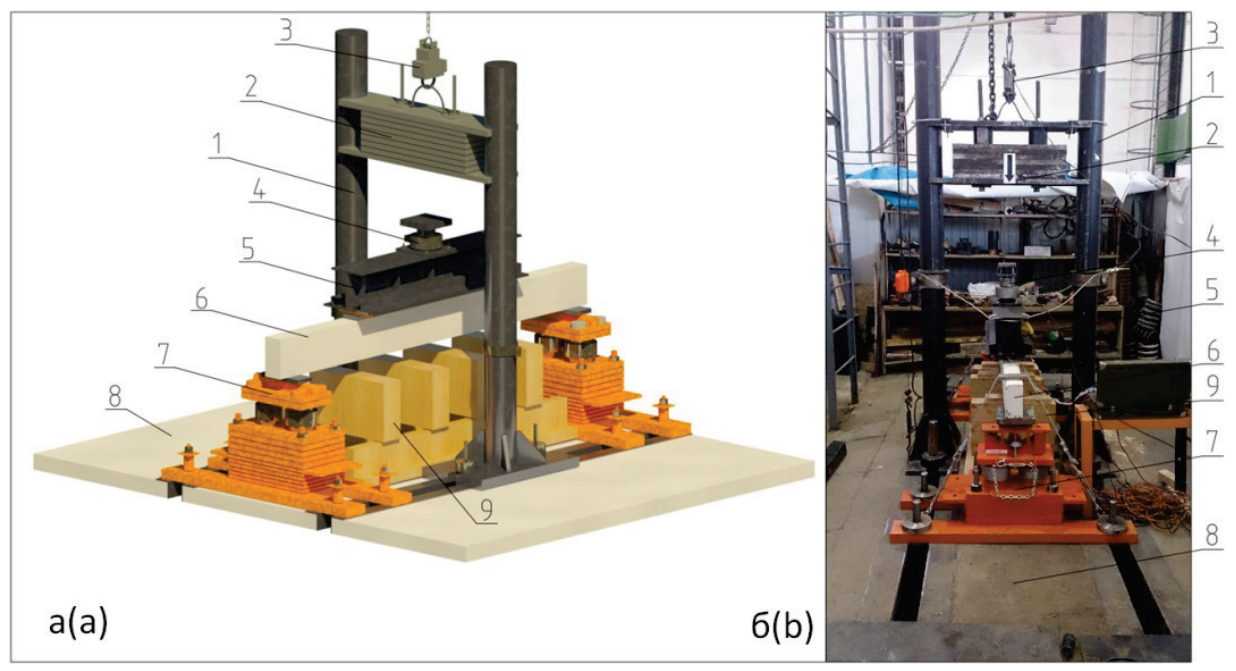

Рис. 1. Общий вид стенда для испытаний: а) модель; б) реализация; 1 - копровая установка; 2 - груз массой 430 кг; 3 - бомбосбрасыватель; 4 - силоизмеритель; 5 - распределительная траверса; 6 - экспериментальный образец; 7 - опора; 8 силовой пол; 9 - система страховки

Fig. 1. General view of the stand for the tests: a) model; b) realization; 1 is the pile driver installation; 2 is the weight of $430 \mathrm{~kg} ; 3$ is the release gear; 4 is the dynomometer; 5 is the distribution traverse; 6 is the experimental sample; 7 is the support; 8 is the floor power; 9 is the insurance system 

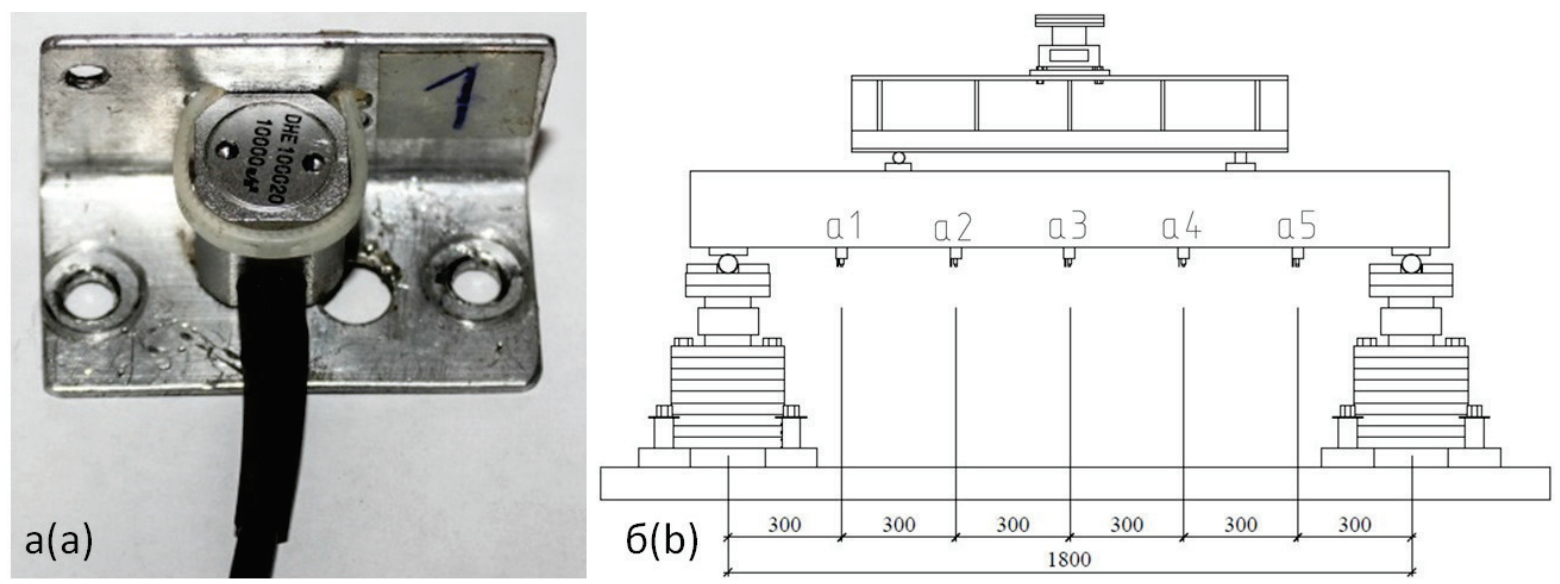

Pис. 2. а) акселерометр ARF-10000A; б) схема расстановки

Fig. 2. a) accelerometer ARF-10000A; b) arrangement scheme
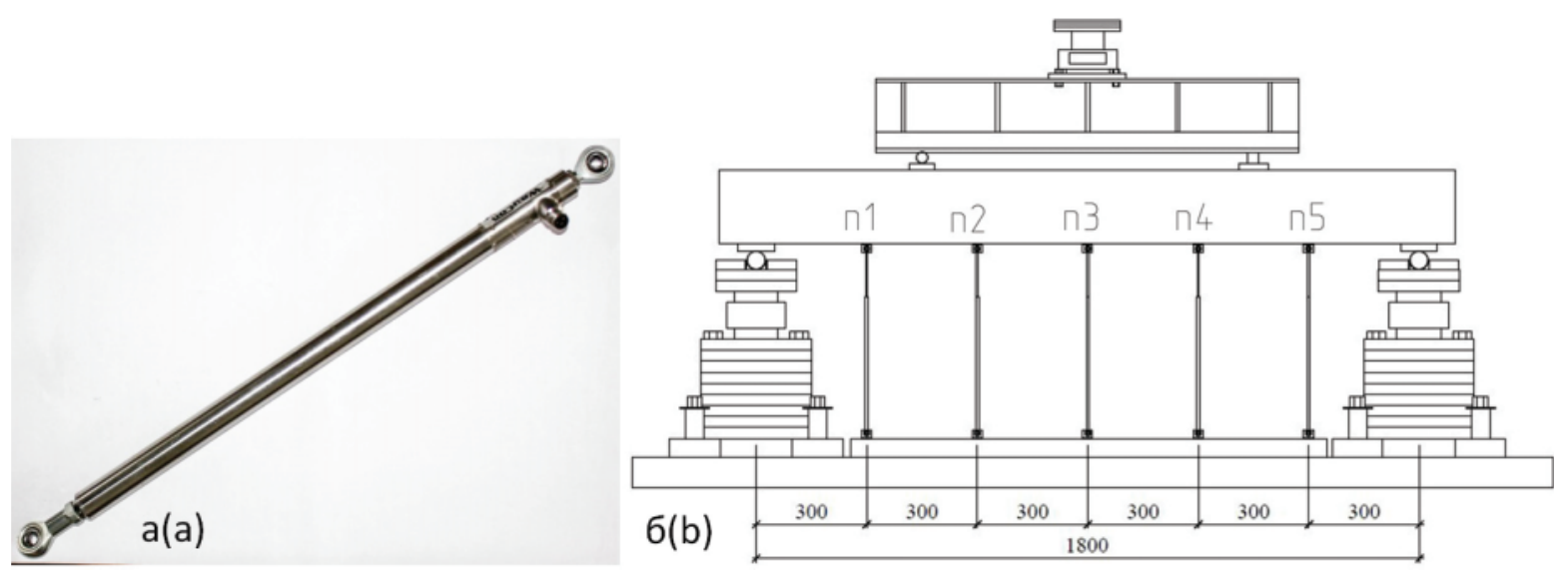

Pис. 3. а) прогибомер WayCon RL150-G-SR; б) схема расстановки

Fig. 3. a) deflectometer WayCon RL150-G-SR; b) arrangement scheme
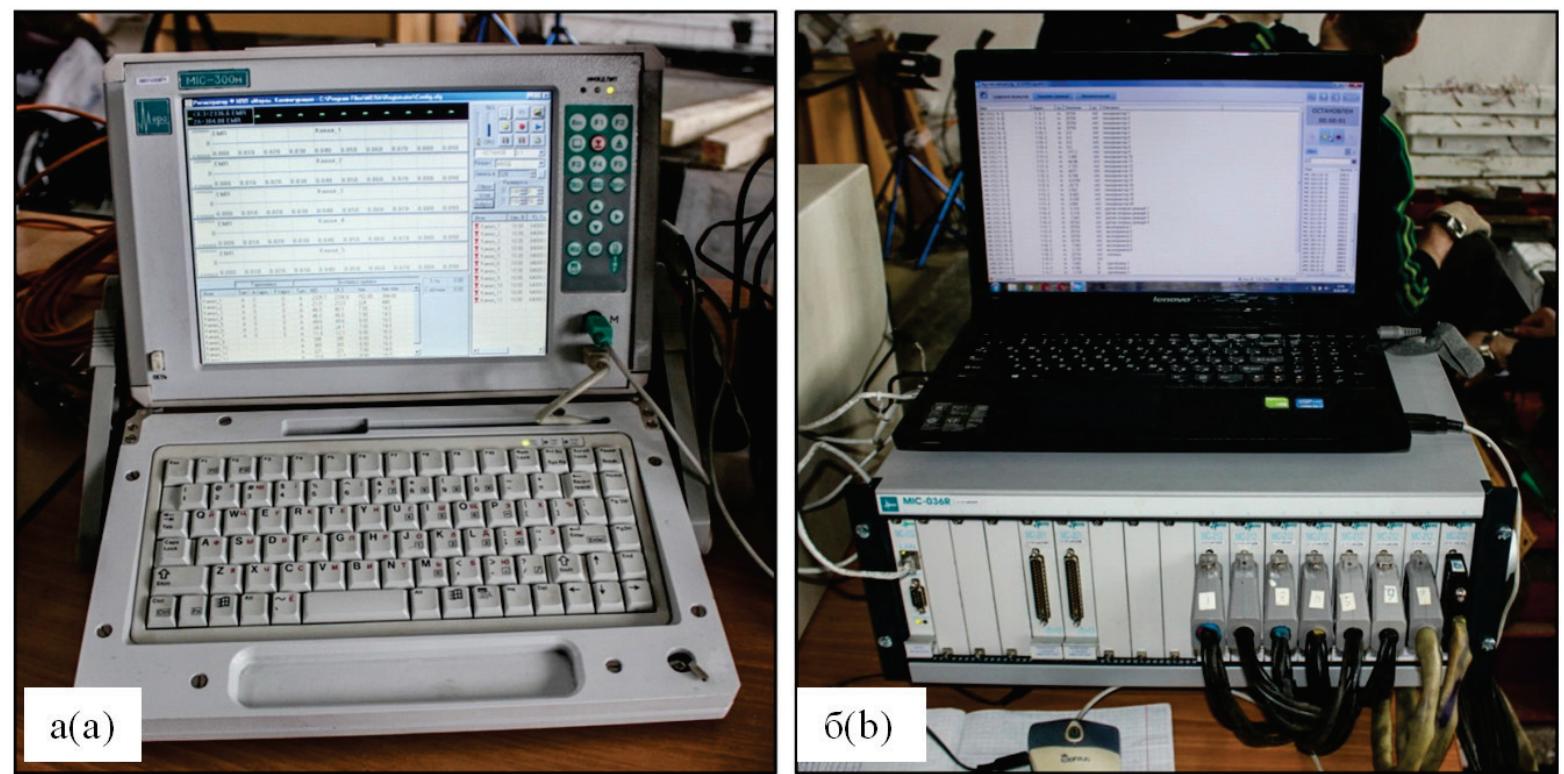

Рис. 4. Измерительные системы: а) MIC-300m; б) MIC-036r

Fig. 4. Measuring systems: a) MIC-300m; b) MIC-036r 


\section{Анализ экспериментальных данных}

Из различных источников, например [31-38], известно, что при кратковременном динамическом воздействии прочность железобетонных конструкций возрастает относительно прочности при статическом действии нагрузки, что объясняется изменением физико-механических характеристик бетона и арматуры. При кратковременном динамическом нагружении происходит неравномерное развитие и некоторое запаздывание деформаций по сравнению с результатами статических испытаний. $К$ тому же в несущих железобетонных элементах при таких воздействиях могут возникать усилия, крутящие моменты и изгибающие моменты двух плоскостей в различных сочетаниях $[39,40]$. Указанное выше, с учетом скоротечности проведения исследований, существенно усложняет процесс регистрации, обработки и анализа данных.

Ранее авторами для оценки работы конструкции при кратковременном динамическом воздействии был предложен подход с использованием коэффициентов результирующей силы [41], где использованы только действующая нагрузка и опорные реакции. В настоящей работе дополнительно использованы такие параметры, как ускорения и прогибы.

После завершения эксперимента полученные исходные сигналы со всех датчиков преобразовывались в формат xls (Microsoft Excel), расчеты и обработка результатов производились в данной программе.

При упругих гармонических колебаниях твердого тела волны ускорения, скорости и координаты (прогибов) взаимосвязаны (рис. 5).

Относительно проведенного авторами эксперимента, исходя из рис. 5 , можно предположить, что:

- в момент удара груза по образцу последний начинает движение, в этот момент его скорость условно максимальна (так как за малый промежуток времени изменяется на конечную величину), далее за некоторый период времени скорость уменьшается до нуля и образец останавливается в точке максимального прогиба, при этом на графике ускорения мы имеем максимyм;

- далее скорость образца снова возрастает, и образец начинает движение вверх, затем скорость падает до нуля и в этот момент на графике перемещений имеем максимальный выгиб образца, на графике ускорения также видно максимальное значение;

- затем в общем случае процесс продолжаться аналогично.

Таким образом, иногда можно охарактеризовать и колебательный процесс, например, при работе технологического оборудования в здании [42].

Однако при реально проведенном эксперименте зарегистрированный график прогибов значительно отличается от графика, представленного для гармонических колебаний упругого тела на рис. 5 . За счёт разрушения внутренних связей материала и проявления пластических деформаций как в бетоне, так и в арматурных стержнях график прогибов «растягивается во времени» и «уходит вниз». В этом случае теряется ярко выраженная закономерность по времени между координатой (прогибом), скоростью и ускорением.

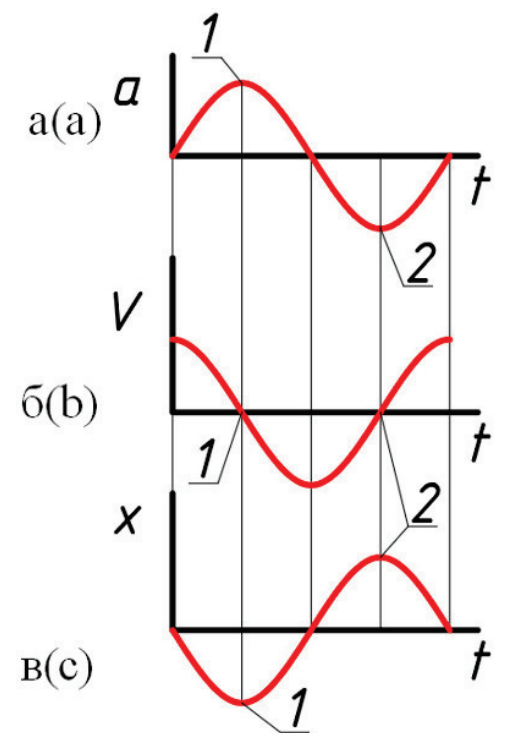

Рис. 5. Форма волны при колебании в общем виде: а) ускорение; б) скорость; в) координата (прогиб); 1 - точка на графике, соответствующая максимальному прогибу образца; 2 - точка на графике, соответствующая максимальному выгибу образца

Fig. 5. Waveform under oscillation in general form: a) acceleration; b) speed; c) coordinate (deflection); 1 is the point on the graph corresponding to the maximum deflection of the sample; 2 is the point on the graph corresponding to the maximum bend of the sample

В связи с тем, что при проведении исследований скорость приборами не регистрировалась (могла быть получена только путем интегрирования сигнала ускорения или дифференцирования сигнала перемещения), за сигналы, по которым можно было выделить временные периоды движения образца вниз и вверх при колебании, оставались сигналы ускорения и прогибов. За основной сигнал авторами был принят сигнал прогибов (как наиболее понятный для интерпретации).

В исследованиях ставилась задача оценить энергетический параметр при движении конструкции в процессе ее деформирования. Соответственно необходимо было определить работу сил на заданных перемещениях в каждый момент времени. Таким образом, нужно было иметь исходные сигналы внешней силы, прогибов, а также ускорений для нахождения возникающих сил инерции. Согласно принципу Даламбера, для составления уравнений равновесия конструкции при динамическом нагружении в расчет необходимо принимать силы инерции.

Из схемы расстановки приборов (рис. 2,3 ) видно, что точки приложения нагрузки непосредственно на образец (места опоры распределитель- 
ной траверсы) располагаются посередине между установленными прогибомерами и акселерометрами 1,2 и 4,5 соответственно. Так как при нахождении работы необходимо оценить действие сил на заданных перемещениях, были вычислены средние значения прогибов и ускорений (по показаниям датчиков п1-п2, п4-п5 и а1-а2, а4-а5 соответственно), тем самым получены необходимые величины в месте приложения сил.

Нагрузка на образец передавалась через силоизмеритель, установленный сверху на распределительной траверсе. В процессе обработки информа- ции было условно принято, что нагрузка на образец передается через опоры распределительной траверсы в равных долях. Для нахождения каждой из этих сил значения, зафиксированные силоизмерителем, делились пополам.

Преобразованные из полученных в ходе экспериментальных исследований сигналы половины действующей силы, ускорений и прогибов в местах приложения нагрузки приведены на рис. 6-8 соответственно,

Анализ графиков на рис. 6-8 показывает, что максимального прогиба образец достиг за время

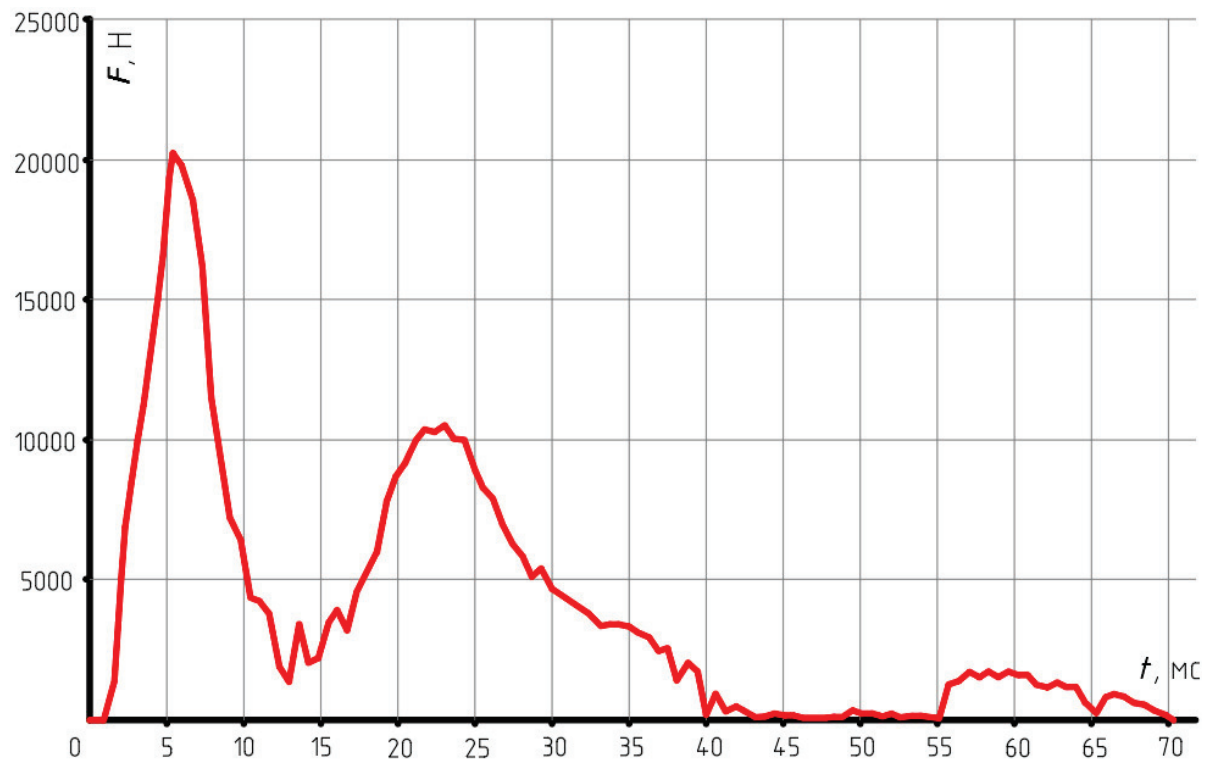

Рис. 6. График изменения половины действующей силы во времени

Fig. 6. Graph of time changes of a half of the acting force

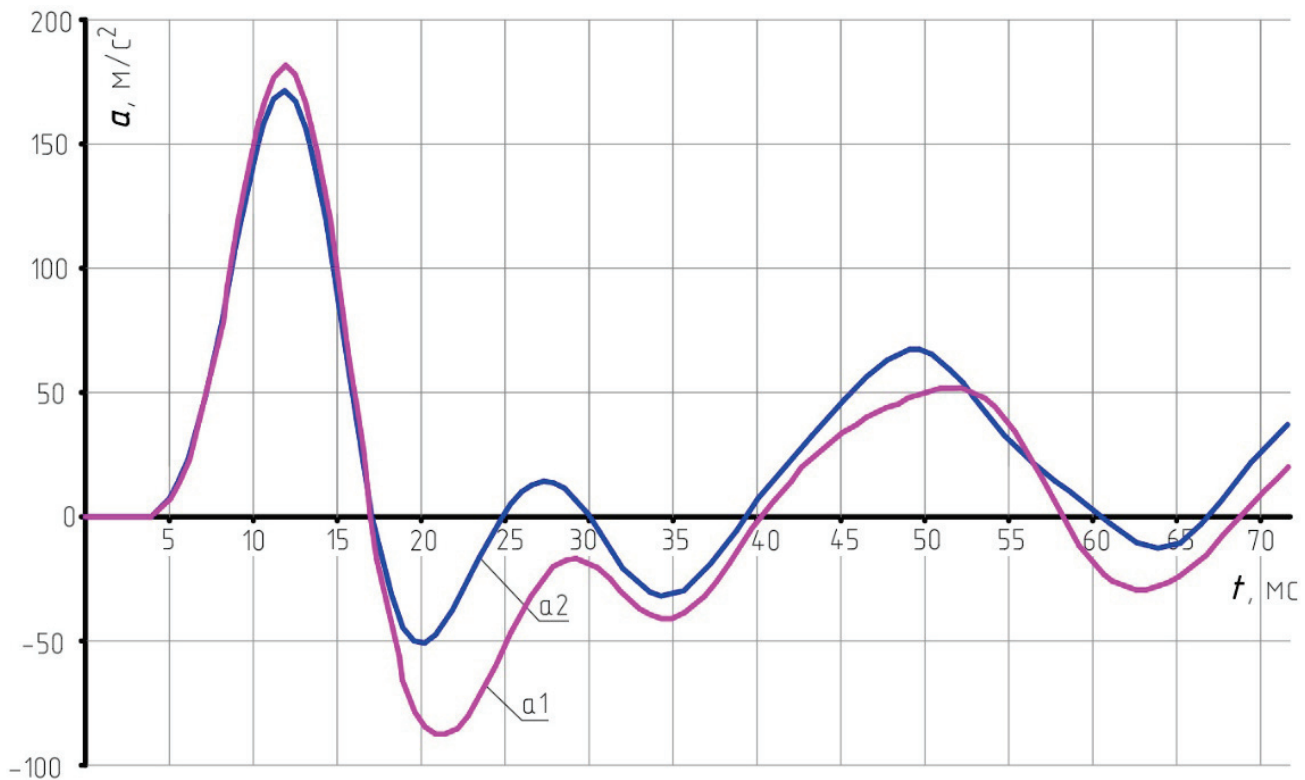

Рис. 7. График изменения ускорений образца в местах приложения нагрузки во времени: 1 - средние значения по показаниям акселерометров а1 и а2; 2 - средние значения по показаниям акселерометров а4 и а5

Fig. 7. Graph of time changes of sample accelerations in places where load is applied: 1 are the average values by indications of the accelerometers a1 and a2; 2 are the average values by indications of the accelerometers a 4 and a5 


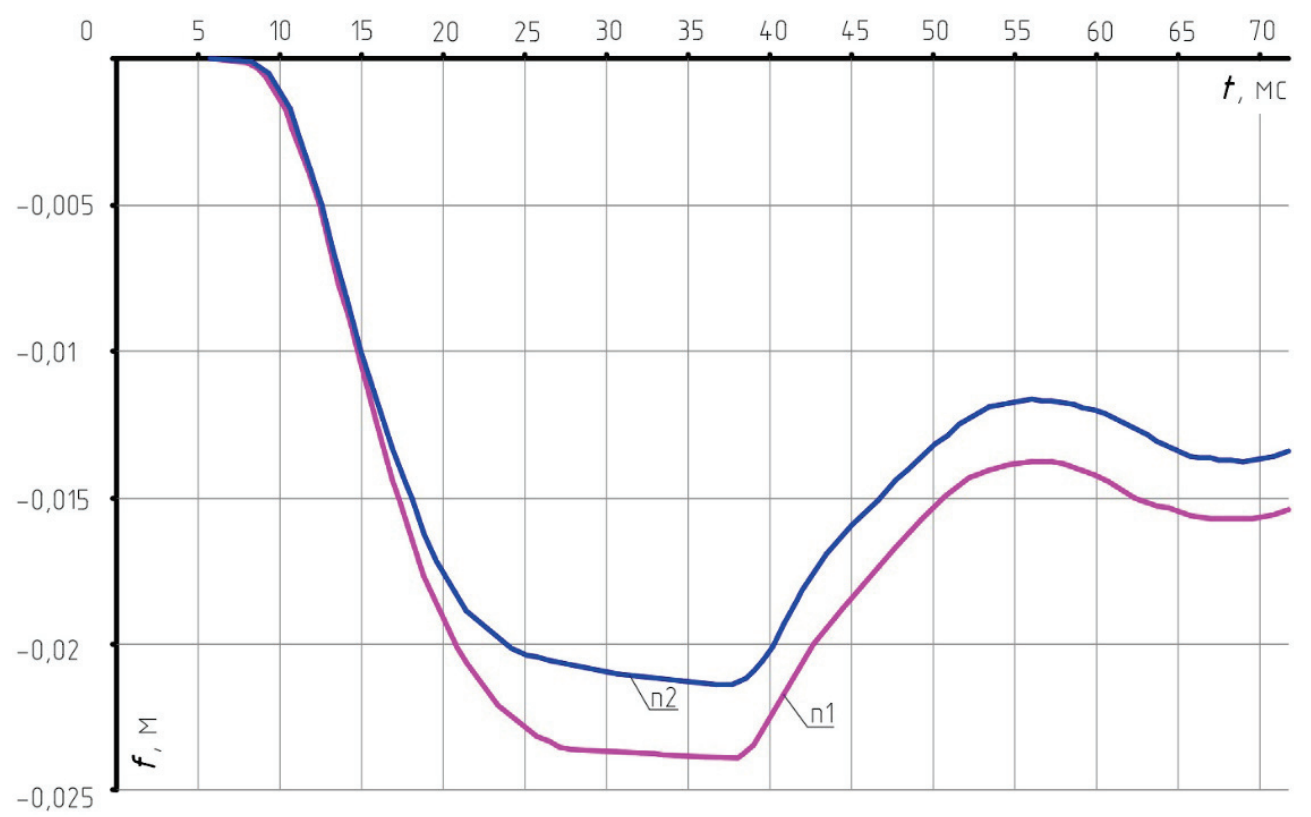

Рис. 8. График изменения прогибов образца в местах приложения нагрузки во времени: 1 - средние значения по показаниям прогибомеров п1 и п2; 2 - средние значения по показаниям прогибомеров п4 и п5

Fig. 8. Graph of time changes of the sample deflections in places where load is applied: 1 are the average values by indications of the deflectometers $n 1$ and $n 2 ; 2$ are the average values by indications of the deflectometers $n 4$ and $\Pi 5$

около 38 мс, что для данного эксперимента примерно соответствует первому периоду колебания сигнала ускорений с акселерометров. Второй период колебания сигнала ускорения завершается около 68 мс и примерно соответствует максимальному (стабилизированному) выгибу образца. Далее продолжается процесс затухающих колебаний. В настоящей работе условно в рассмотрение было принято два периода колебаний сигнала ускорений, примерно соответствующих однократному прогибу и выгибу образца (для конкретного эксперимента). В связи с этим все представленные графики и зависимости приведены за время порядка $70 \mathrm{Mc}$.

Тут нужно отметить, что дополнительный всплеск сигнала ускорений в период времени 25-30 мс связан, вероятно, с несовершенством экспериментальной установки, проявляющимся в отскоке груза и его повторном падении.

Также нельзя исключать влияние на показания датчиков шумов от перемещения опорных пластин и других металлических элементов стенда. Известно, что невозможно произвести идеальный вибродатчик, вообще не чувствительный к условиям окружающей среды и их изменениям. В рамках описанного исследования причинами погрешностей могут быть: деформации основания (железобетонная балка), податливость крепления датчика, поперечные колебания, а также изменения температуры и влажность. Хотя, исходя из скоротечности времени проведения эксперимента, последний параметр можно практически исключить.
Для повышения достоверности результатов необходимо собрать стенд, исключающий отскок груза, и получить результаты при чистом однократном ударе.

В начальный момент времени ускорения направлены в одну сторону, а силы инерции в другую, согласно формуле (1):

$$
F_{\text {ин }}=-m a .
$$

При эксперименте силоизмеритель располагался на распределительной траверсе и измерял все приходящиеся на него силы, а силы инерции от массы распределительной траверсы, опытного образца и самого силоизмерителя необходимо было определить. Общая их масса составляла 165 кг. В рамках настоящей работы силы инерции условно были найдены как произведение половины массы на средние значения ускорений (рис. 8) в точках приложения нагрузки на образец с обратным знаком. График изменения сил инерции, полученный описанным способом за выбранный для рассмотрения период времени, приведен на рис. 9 .

Далее на периоде времени 70 мс был построен график работы сил на заданных перемещениях. В соответствие с теоремой Клайперона, при воздействии на инженерную конструкцию группы внешних сил работа этих сил равна половине суммы произведений каждой силы на величину соответствующего ей перемещения, вызванного действием всей группы сил. Формулу для определения работы в каждый момент времени (2) можно представить в виде: 


$$
\begin{gathered}
A(t)=\frac{\left(F_{\text {сил }}(t) / 2+F_{\text {ин } 1}(t)\right) f_{1}(t)}{2}+ \\
+\frac{\left(F_{\text {сил }}(t) / 2+F_{\text {ин } 2}(t)\right) f_{2}(t)}{2},
\end{gathered}
$$

где $A(t)$ - работа сил на заданных перемещениях в каждый момент времени, Дж; $F_{\text {сил }}(t) / 2$ - сила, зафиксированная силоизмерителем при испытании, деленная на 2 для получения величины силы в ме- сте передачи ее на образец через опоры распределительной траверсы в каждый момент времени, Н; $F_{\text {нн1 }}(t), F_{\text {ин2 }}(t)$ - условные силы инерции, сведенные в места приложения сил на образец в каждый момент времени, $\mathrm{H} ; f_{1}(t), f_{2}(t)$ - прогибы образца в месте передачи на него внешних сил в каждый момент времени, м.

Полученный график работы за время 70 мс приведен на рис. 10.

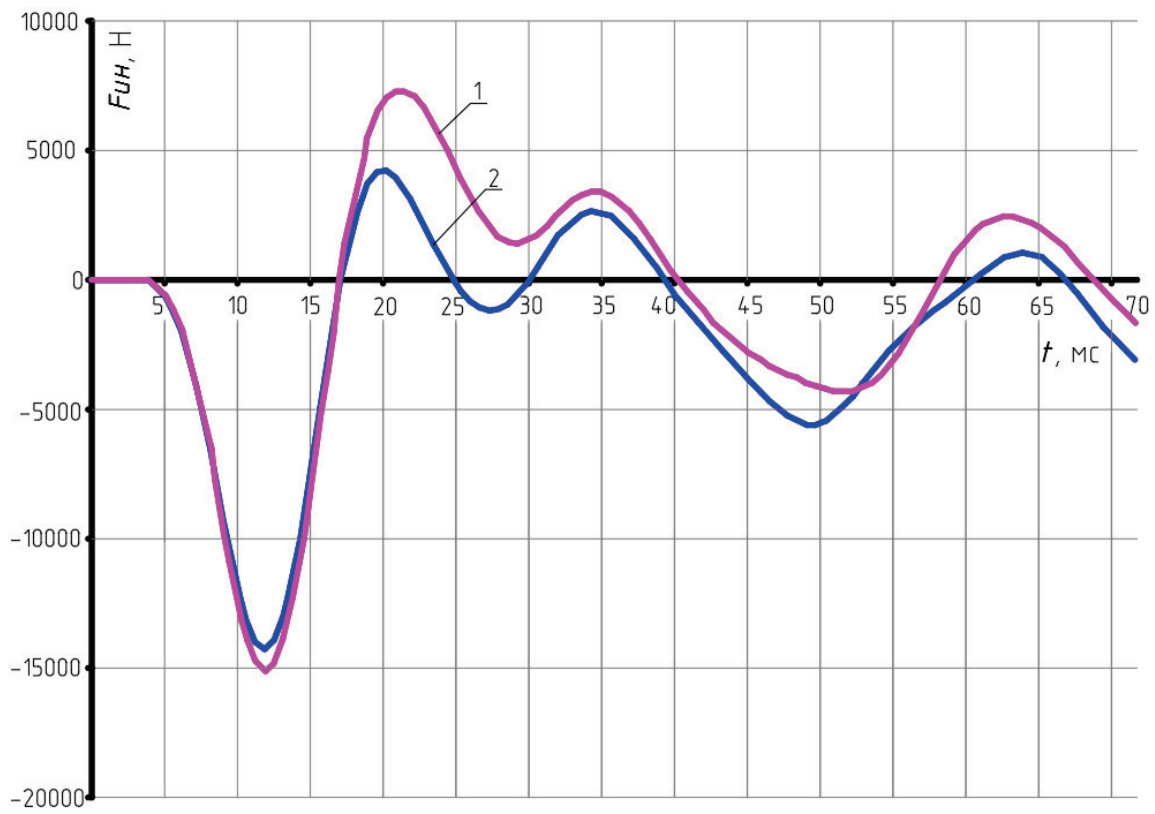

Рис. 9. График изменения сил инерции во времени: 1 - средние значения, полученные с учетом данных акселерометров а1 и a2; 2 - средние значения, полученные с учетом данных акселерометров а4 и а5

Fig. 9. Graph of time changes of the inertia forces: 1 are the average values obtained taking into account the data of accelerometers a1 and a2; 2 are the average values obtained taking into account the data of accelerometers a 4 and a5

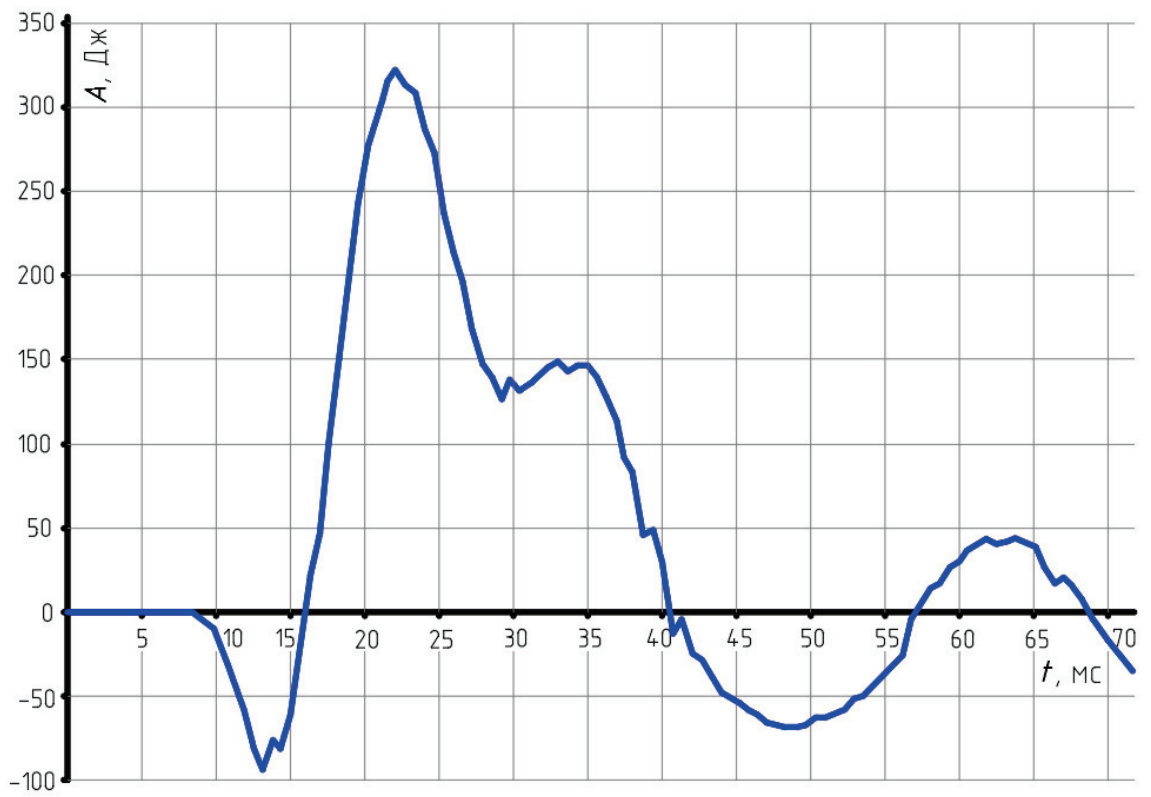

Рис. 10. График изменения работы за период времени 70 мс

Fig. 10. Graph of work time changes over a period of $70 \mathrm{~ms}$ 


\section{Способ оценки степени живучести}

В представленном экспериментальном исследовании рост внутренней энергии образца обусловлен увеличением потенциальной энергии, которая связана со взаимным расположением молекул тела при его прогибе. Если мы имеем дело с упругой деформацией, то после снятия нагрузки, за счет внутренней энергии, силы упругости совершают работу, осуществляя выгиб образца.

Известно, что в ходе упругой деформации температура твердых тел существенно не увеличивается, а при пластической деформации твердые тела могут значительно увеличивать свою температуру. В повышении температуры, следовательно, кинетической энергии молекул, отражается рост внутренней энергии тела при пластической деформации. При этом увеличение внутренней энергии происходит также за счет работы сил, вызывающих деформацию.

Если оценить разницу между энергией за временной период, характеризующий движение образца вниз (до максимального прогиба), и энергией упругой деформации, благодаря которой образец перемещается вверх (временной период от максимального прогиба до максимально выгиба), можно, исходя из закона сохранения энергии, сделать вывод о суммарном объеме энергии, затраченном на разрушение (пластическую деформацию), колебательное движение соударяющихся тел, энергию, перешедшую в выделение тепла и пр.

Учет и точное разложение энергии на все указанные составляющие при кратковременном динамическом воздействии технически и математически осуществить очень сложно.

Поэтому в рамках практического применения для оценки живучести экспериментального образ- ца авторами предложен коэффициент степени живучести, выражающий отношение полной переданной энергии к энергии упругой деформации твердого тела при одном полном колебании (прогиб и выгиб).

Для получения энергии необходимо найти площадь под графиком зависимости работы от времени (рис. 10) за необходимые отрезки времени (прогиб и выгиб). Это можно сделать графическим способом или аналитическим - путем интегрирования.

Вычислить значение коэффициента степени живучести можно по аналитической зависимости (3), приведенной ниже:

$$
k_{\text {с. } \%}=\frac{\int_{\pi}^{\mathrm{B}}|A(t)| d t}{\int_{0}^{\pi}|A(t)| / d t},
$$

где $k_{\text {с.ж }}$ - коэффициент степени живучести образца; $A$ - работа сил на заданных перемещениях в каждый момент времени, Дж; п - время максимального прогиба, с; в - время максимального (стабилизированного) выгиба, с.

В графическом виде нахождение коэффициента степени живучести для образца проведенных исследований приведено на рис. 11. Здесь для удобства отображения информации значения работы переведены в относительные единицы путем деление на максимальную величину $-A_{\max }-$ максимальное значение работы сил на заданных перемещениях за весь временной период вычислений, Дж. На рис. 11 площадь $S_{1}$ (заштрихованная красным цветом) соответствует полной относительной энергии, а площадь $S_{2}$ (заштрихованная зеленым

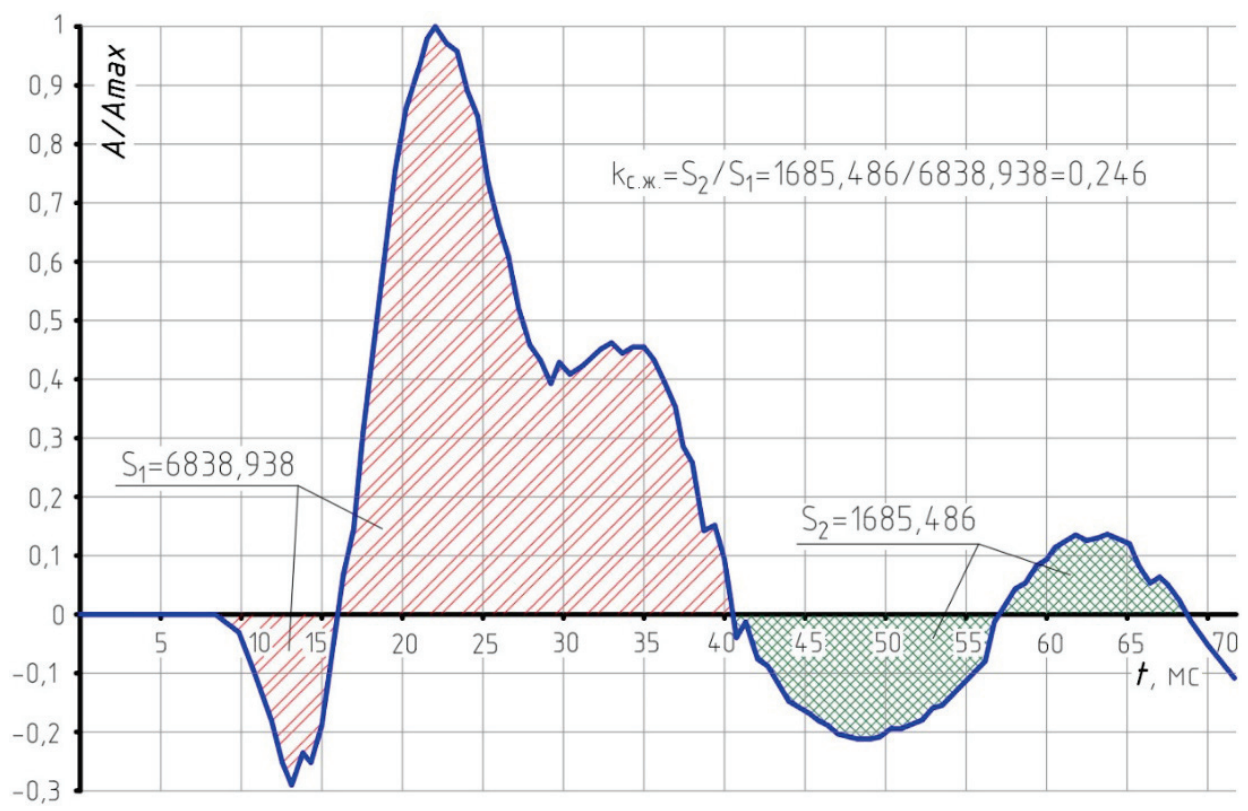

Рис. 11. График для нахождения коэффициента степени живучести

Fig. 11. Graph for finding the survivability coefficient 
цветом) - относительной энергии упругой деформации образца. Для получения абсолютных значений энергий из графика необходимо умножать соответствующие площади на значение $A_{\max }$.

Как видно из рис. 11 для представленного в качестве примера испытания, значение коэффициента степени живучести образца составило $k_{\text {с.ж }}=0,246$.

Использование приведенного подхода позволяет получить качественную и количественную картину процесса распределения энергии при кратковременном динамическом воздействии на изгибаемый железобетонный образец и оценку степени живучести образца, выраженную через коэффициент степени живучести.

Разработанная методика и коэффициент степени живучести могут быть полезны, например, при проектировании и оценке эффективности защитных систем на податливых опорах и систем, гасящих колебания для смягчения динамического воздействия на железобетонные конструкции при сейсмических, аварийных ударных или взрывных нагрузках [43-50].

Теоретически можно вычислить значение коэффициента степени живучести на всем временном интервале колебания образца - до полной остановки, однако процесс вычисления сильно усложняется, а амплитуды последующих колебаний значительно меньше, чем при первом прогибе и выгибе образца вследствие затухания колебаний

\section{СПИСОК ЛИТЕРАТУРЫ}

1. Стекольников Ю.И. Живучесть систем. - СПб.: Политехника, 2002. $-155 \mathrm{c}$

2. Odnokopylov G.I., Bragin A.D. Fault tolerant vector control of induction motor drive (Article number 012015) // IOP Conference Series: Materials Science and Engineering. - 2014. - V. 66. № 1. - P. 1-6.

3. Odnokopylov G.I., Rozaev I.A. Formation of failure matrix and failure-free control algorithm for multi-sectioned Switched-reluctance drive (Article number 012035) // IOP Conference Series: Materials Science and Engineering. - 2014. - V. 66. - № 1. P. 1-7.

4. Odnokopylov G.I., Bragin A.D. Mathematical model of brushless DC motor in phase loss operation mode // Applied Mechanics and Materials. - 2015. - V. 698. - P. 24-29.

5. Odnokopylov G.I., Bragin A.D. Algorithms of fault tolerant control of induction motor electric drive in phase loss operate mode // 2015 International Siberian Conference on Control and Communications (SIBCON): proceedings. - Omsk, May 21-23, 2015. Novosibirsk: IEEE Russia Siberia Section, 2015. - P. 1-5.

6. Odnokopylov G.I., Rozaev I.A. Fault-tolerant control of switched-reluctance drive in emergency modes // 2015 International Siberian Conference on Control and Communications (SIBCON): proceedings. - Omsk, May 21-23, 2015. - Novosibirsk: IEEE Russia Siberia Section, 2015. - P. 1-6.

7. Odnokopylov G.I., Rozaev I.A. Fault-tolerant control algorithms of switched-reluctance motor drive in open-phase modes // 2016 The $11^{\text {th }}$ International Forum on Strategic Technology (IFOST): proceedings. - Novosibirsk, Jun 1-3, 2016. P. $140-144$.

8. Short and long term cracking behavior of GFRP reinforced concrete beams / C. Mias, L. Torres, M. Guadagnini, A. Turon // Composites Part B: Engineering. - 2015. - V. 77. - P. 223-231. (то есть погрешность вычислений, вероятно, будет не значительной). Таким образом, в целях практического применения коэффициент степени живучести рекомендуется оценивать только за временной интервал, соответствующий одному полному периоду колебания образца (прогиб-выгиб).

Для получения более полных данных о процессе распределения энергии, происходящего в ходе кратковременного динамического воздействия на железобетонный образец, необходимо оценить деформации бетона и арматуры экспериментального образца и выйти через них на объем энергии разрушения (энергии пластического деформирования).

Разработанная методика может быть применена для оценки степени живучести различных классов строительных конструкций, а также при различных временных интервалах ее действия.

\section{Выводы}

1. Предложен способ оценки степени живучести ответственных строительных конструкций зданий и сооружений при ударно-волновом нагружении, с применением коэффициента степени живучести на основе энергетического параметра.

2. На примере конкретного испытания изгибаемого железобетонного элемента на кратковременную динамическую нагрузку получено значение коэффициента степени живучести, которое составило $k_{\text {с.ж }}=0,246$.

9. Lou T., Lopes S.M.R., Lopes A.V. FE analysis of short- and longterm behavior of simply supported slender prestressed concrete columns under eccentric end axial loads causing uniaxial bending // Engineering Structures. - 2015. - V. 85. - P. 52-62.

10. Correlation analysis of accelerated aging and natural aging of GFRP in reinforced concrete beams / J. Dong, X. He, H. Zhang, J. Zhang, Y. Yang, Y. Song, J. Rao // Journal of Wuhan University of technology (Transportation Science and Engineering). 2017. - V. 41. - № 2. - P. 312-317.

11. Method of measurement of the dynamic strength of concrete under explosive loading / A.S. Savinykh, G.V. Garkushin, S.V. Razorenov, G.I. Kanel // International Journal of Fracture. 2018. - V. 209. - P. 109-115.

12. A comment on the calculation models for reinforced concrete under intense dynamic loading / F. Gao, M. Wang, X. Zhang, Y. He, M. Li // Baozha Yu Chongji. - 2017. - V. 37. - № 2. P. $365-376$.

13. Demyanov A., Kolchunov V.I. The dynamic loading in longitudinal and transverse reinforcement at instant emergence of the spatial crack in reinforced concrete element under the action of a torsion with bending // Journal of Applied Engineering Science. 2017. - V. 15. - № 3. - P. 381-386.

14. Mesoscopic simulation of the dynamic tensile behaviour of concrete based on a rate-dependent cohesive model / W. Zhou, L. Tang, G. Ma, X. Liu, M. Chen // International Journal of Impact Engineering. - 2016. - V. 95. - P. 165-175.

15. Li H.-Y., Teng J., Li Z.-H. An efficient platform HSNAS (GPU) for nonlinear static and dynamic analysis of reinforced concrete frames-II. Program verification and analysis // Zhendong yu Chongji. - 2016. - V. 35. - № 14. - P. 54-60.

16. Chen X., Chen C., Xu L., Shao Y. Dynamic flexural strength of concrete under high strain rates // Magazine of Concrete Research. - 2017. - V. 69. - № 3. - P. 109-119. 
17. Гениев Г.А. 0 влиянии продолжительности действия нагрузки на прочность материала // Бетон и железобетон. - 1996. № 4. - C. 19-22.

18. Плевков В.С. Динамическая прочность бетона и арматуры железобетонных конструкций. - Томск: Изд-во Том. гос. архит.строит. ун-та, 1996. - 64 с.

19. Беспаев А.А., Куралов У.С., Алтигенов У.Б. Исследование работы изгибаемых железобетонных конструкций, усиленных фиброармированными пластиками, при динамических воздействиях // Сейсмостойкое строительство. Безопасность сооружений. - 2015. - № 3. - С. 43-45.

20. Исследование механических свойств мелкозернистого бетона при динамическом нагружении / А.М. Брагов, А.Ю. Константинов, А.К. Ломунов, Д.А. Ламзин // Приволжский научный журнал. - 2014. - № 4 (32). - С. 11-21.

21. Тамразян А.Г., Аветисян Л.А. Расчет внецентренносжатых железобетонных элементов на кратковременную динамическую нагрузку // Строительство: наука и образование. 2013. - № 4. - C. 2-6.

22. Барбашев Н.П. Расчет железобетонной арки в грунте на действие динамической нагрузки // Вестник МГСУ. - 2016. № 1. - C. 35-43.

23. Тамов М.А. Расчет железобетонный изгибаемых элементов, армированных высокопрочными сталями, на динамические нагрузки. Депонированная рукопись № 3016 01.02.1982.

24. Тамразян А.Г., Аветисян Л.А. Прочность и несущая способность сжатых железобетонных элементов при динамическом нагружении в условиях повышенных температур // Промышленное и гражданское строительство. - 2016. - № 7. C. $56-60$.

25. Сембаев Б.Н., Грушевский К.Е. Методы расчета железобетонных конструкций на динамические нагрузки // Управление Социально-Экономическими Системами: Теория, Методология, Практика: сборник статей Международной научно-практической конференции: в 2 ч. - М., 2017. - С. 45-47.

26. Experimental-theoretical investigation of fiber reinforced concrete under dynamic loading / A.M. Bragov, A.Yu. Konstantinov, Yu.V. Petrov, I.V. Smirnov, B.L. Karihaloo, D.A. Lamzin, A.K. Lomunov // Fib Symposium TEL-AVIV 2013: Engineering a Concrete Future: Technology, Modeling and Construction. - TelAviv, 2013. - C. 633-636.

27. Berlinov M. Developing the phenomenological equations triaxial deformation of concrete under dynamic loads // MATEC Web of Conferences International Science Conference SPbWOSCE-2016 «SMART City». - St-Petersburg, EDP Science, 2017. - P. 1-9.

28. Snozzi L., Molinari J.F., Gatuingt F. A meso-mechanical model for concrete under dynamic tensile and compressive loading // International Journal of Fracture. - 2012. - V. 178. - № 1-2. C. $179-194$.

29. Research on dynamic mechanical properties of alkali activated slag concrete under temperature-loads coupling effects / W.-J. Long, J.-J. Wei, Y.-C. Gu, F. Xing // Construction and Building Materials. - 2017. - V. 154. - P. 687-696.

30. Kotronis P., Mazars J., Davenne L. The equivalent reinforced concrete model for simulating the behavior of walls under dynamic shear loading // Engineering Fracture Mechanics. - 2003. V. 70. - № 7-8. - C. 1085-1097.

31. Родевич В.В., Арзамасцев С.А. К оценке прочности железобетонных изгибаемых элементов при кручении от кратковременных динамических нагрузок // Вестник Томского государственного архитектурно-строительного университета. 2017. - № 2 (61). - C. 112-122.

32. Кумпяк 0.Г., Галяутдинов 3.Р. Расчет железобетонных плит на кратковременные динамические нагрузки с учетом реальных свойств материалов // Бетон и железобетон. - 2007. № 6. - C. $15-18$.
33. Уткин Д.Г. Деформирование изгибаемых сталефиброжелезобетонных элементов со смешанным армированием при кратковременном динамическом нагружении // Вестник Томского государственного архитектурно-строительного университета. 2015. - № 5 (52). - C. 80-89.

34. Уткин Д.Г., Григорьев Д.В., Зайцев И.А. Определение прочностных и деформативных свойств сталефибробетона при статическом и кратковременном динамическом нагружениях // Вестник Томского государственного архитектурно-строительного университета. - 2016. - № 6 (59). - С. 139-149.

35. Попов Н.Н., Расторгуев Б.С. Вопросы расчета и конструирования специальных сооружений. - М.: Стройиздат, 1980. $190 \mathrm{c.}$.

36. Попов Н.Н., Расторгуев Б.С. Расчет железобетонных конструкций на действие кратковременных динамических нагрузок. - М.: Стройиздат, 1964. - 151 c.

37. Особенности разрушения железобетонных конструкций при динамическом нагружении / В.С. Плевков, А.В. Радченко, И.В. Балдин, П.А. Радченко, М.Е. Гончаров, С.П. Батуев // Вестник Тамбовского Университета. - 2013. - Т. 18. Вып. 4. - C. 1578-1579.

38. Calculation of reinforced-concrete frame strength under a simultaneous static cross section load and a column lateral impact / N. Belov, D. Kopanitsa, A. Yugov, S. Kaparulin, A. Plyaskin, A. Kalichkina, A. Ustinov, N. Yugov, G. Kopanitsa // AIP Conference Proc. Advanced Materials in Technology and Construction. - Tомск, 2016. - P. 47-53.

39. Саркисов Д.Ю. Прочность и деформативность железобетонных элементов при косом внецентренном кратковременном динамическом сжатии, растяжении и изгибе // Вестник Томского государственного архитектурно-строительного университета. - 2008. - № 3. - С. 134-143.

40. Плевков В.С., Саркисов Д.Ю., Тигай 0.Ю. Исследование железобетонных элементов при косом внецентренном кратковременном динамическом сжатии, растяжении и изгибе // Известия Орловского государственного технического университета. Серия: Строительство и транспорт. - 2008. - № 3-19. C. $33-37$.

41. Однокопылов Г.И., Саркисов Д.Ю. Оценка параметров разрушающей нагрузки при ударно-волновом нагружении для ответственных строительных конструкций сооружений нефтегазового комплекса // Известия Томского политехнического университета. Инжиниринг георесурсов. - 2017. - Т. 328. № 3. - C. $85-95$.

42. Плевков В.С., Саркисов Д.Ю., Балдин С.В. Анализ параметров колебательных процессов несущего каркаса производственного здания // Строительство и реконструкция. - 2017. № 4 (72). - C. $47-56$.

43. Experimental analysis and modeling of two-way reinforced concrete slabs over different kinds of yielding supports under shortterm dynamic loading / B. Chiaia, 0. Kumpyak, L. Placidi, V.B. Maksimov // Engineering Structures. - 2015. - № 96. P. 88-99.

44. Mescheulov N., Kumpyak 0., Lyulevich Y. Deformability of oblique sections of rc beams on yielding supports under dynamic impact // AIP Conference Proc. Youth, Science, Solutions: Ideas and Prospects. - Tomsk, 2017. - P. 1-8.

45. Galyautdinov Z.R. Deformation of reinforced concrete slabs on yielding supports under short-time dynamic loading // AIP Conference Proc. Youth, Science, Solutions: Ideas and Prospects. Tomsk, 2017. - P. 40-44.

46. Kumpyak 0.G., Mescheulov N.V. Numerical simulation of yielding supports in the shape of annular tubes under static and short-term dynamic loading // International Journal for Computational Civil and Structural Engineering. - 2017. - V. 13. № 4. - P. 103-113. 
47. Kumpyak 0.G., Galyautdinov Z.R., Kokorin D.N. Strength of concrete structures under dynamic loading // AIP Conference Proc. Advanced Materials in Technology and Construction. Tomsk, 2016. - P. 59-68.

48. Кумпяк О.Г, Галяутдинов З.Р., Кокорин Д.Н. Прочность и деформативность железобетонных конструкций на податливых опорах при кратковременном динамическом нагружении: монография. - Томск: Изд-во Том. гос. архит.-строит. ун-та, 2016. -272 c

49. Анализ динамического деформирования железобетонных балок на податливых опорах / З.Р. Галяутдинов, М.М. Боглаева, Д.Р. Галяутдинов, Е.В. Рюмин // Наука и образование в жиз- ни современного общества: сборник научных трудов по материалам Международной научно-практической конференции: в 18 ч. - Томск, 2013. - С. 49-52.

50. Галяутдинов 3.Р. Исследование работы железобетонных плит на податливых опорах при кратковременном динамическом нагружении // Безопасность строительного фонда России. Проблемы и решения: Материалы Международных академических чтений. Курский государственный университет. Курск, 2015. - C. 130-138.

\section{Информация об авторах}

Однокопылов Г.И., доктор технических наук, доцент отделения электроэнергетики и электротехники Национального исследовательского Томского политехнического университета.

Саркисов Д.Ю., кандидат технических наук, доцент кафедры железобетонных и каменных конструкций Томского государственного архитектурно-строительного университета.

Бутузов $\boldsymbol{E} . \boldsymbol{A}$., магистрант Томского государственного архитектурно-строительного университета. 
UDC 69.058 .8

\title{
EVALUATION OF SURVIVABILITY DEGREE OF RESPONSIBLE BUILDING STRUCTURES UNDER SHOCK WAVE LOADING
}

\author{
Georgy I. Odnokopylov', \\ OGIz@yandex.ru \\ Dmitriy Yu. Sarkisov², \\ Milandd@yandex.ru \\ Egor A. Butuzov , \\ egorko18m@gmail.com \\ 1 National Research Tomsk Polytechnic University, \\ 30, Lenin Avenue, Tomsk, 634050, Russia. \\ 2 Tomsk State University of Architecture and Building, \\ 2, Solyanaya Square, Tomsk, 634003, Russia.
}

The relevance of the research is caused by technical complication of oil and gas complex objects, owing to the increase in the volumes and speed of extraction of raw materials, which may be affected by shock wave loads in abnormal situations. The causes of the impact may be explosions, heavy cargo drops, terrorist acts, natural and man-made disasters, etc. These situations with a high probability lead to significant damage to the building structures of industrial buildings. To ensure further functioning of the structure, it is necessary to design the building structures and the object as a whole that have survivability properties under non-stationary influence. Accounting for such properties should be analyzed in the construction of scenarios for the emergence and development of contingencies, as well as in the analysis of risks. Thus, the development of methods for assessing the survivability of building structures under shock-wave action is an urgent task.

The main aim of the study is to develop a practically applicable method for assessing the survivability of a building structure under shortterm shock wave loading based on an analysis of the energy parameter.

The methods: measurement of accelerations, deflections and loads by tensometry methods, graph analysis method using Microsoft Excel software.

The results. The authors have been developed the technique to assess the survivability of a building structure under shock wave loading, for responsible building structures of oil and gas facilities with the use of survivability coefficient. On the example of test of a reinforced concrete element for a short-term dynamic load, the values of the indicated coefficient were obtained. The authors made proposals for using the survivability coefficient in the design of building structures which may be affected by short-term dynamic loads.

Key words:

Survivability degree, destruction energy, work, short-term dynamic load, shock-wave loading, reinforced concrete, experimental study.

\section{REFERENCES}

1. Stekolnikov Yu.I. Zhivuchest sistem [Survivability of systems.] St-Petersburg, Politekhnika Publ., 2002. 155 p.

2. Odnokopylov G.I., Bragin A.D. Fault tolerant vector control of induction motor drive (Article number 012015). IOP Conference Series: Materials Science and Engineering, 2014, vol. 66, no. 1, pp. 1-6.

3. Odnokopylov G.I., Rozaev I.A. Formation of failure matrix and failure-free control algorithm for multi-sectioned Switched-reluctance drive (Article number 012035). IOP Conference Series: Materials Science and Engineering, 2014, vol. 66, no. 1, pp. 1-7.

4. Odnokopylov G.I., Bragin A.D. Mathematical model of brushless DC motor in phase loss operation mode. Applied Mechanics and Materials, 2015, vol. 698, pp. 24-29.

5. Odnokopylov G.I., Bragin A.D. Algorithms of fault tolerant control of induction motor electric drive in phase loss operate mode. International Siberian Conference on Control and Communications (SIBCON): proceedings. Omsk, May 21-23, 2015. Novosibirsk, IEEE Russia Siberia Section, 2015. pp. 1-5.

6. Odnokopylov G.I., Rozaev I.A. Fault-tolerant control of switched-reluctance drive in emergency modes. International Siberian Conference on Control and Communications (SIBCON): proceedings. Omsk, May 21-23, 2015. Novosibirsk, IEEE Russia Siberia Section, 2015. pp. 1-6.
7. Odnokopylov G.I., Rozaev I.A. Fault-tolerant control algorithms of switched-reluctance motor drive in open-phase modes. The $11^{\text {th }}$ International Forum on Strategic Technology (IFOST): proceedings. Novosibirsk, Jun 1-3, 2016. pp. 140-144.

8. Mias C., Torres L., Guadagnini M., Turon A. Short and long term cracking behavior of GFRP reinforced concrete beams. Composites Part B: Engineering, 2015, vol. 77, pp. 223-231.

9. Lou T., Lopes S.M.R., Lopes A.V. FE analysis of short- and longterm behavior of simply supported slender prestressed concrete columns under eccentric end axial loads causing uniaxial bending. Engineering Structures, 2015, vol. 85, pp. 52-62.

10. Dong J., He X., Zhang H., Zhang J., Yang Y., Song Y., Rao J. Correlation analysis of accelerated aging and natural aging of GFRP in reinforced concrete beams. Journal of Wuhan University of technology (Transportation Science and Engineering), 2017, vol. 41, no. 2, pp. 312-317.

11. Savinykh A.S., Garkushin G.V., Razorenov S.V., Kanel G.I. Method of measurement of the dynamic strength of concrete under explosive loading. International Journal of Fracture, 2017, vol. 209, pp. 109-115.

12. Gao F., Wang M., Zhang X., He Y., Li M. A comment on the calculation models for reinforced concrete under intense dynamic loading. Baozha Yu Chongji, 2017, vol. 37, no. 2, pp. 365-376.

13. Demyanov A., Kolchunov V.I. The dynamic loading in longitudinal and transverse reinforcement at instant emergence of the spa- 
tial crack in reinforced concrete element under the action of a torsion with bending. Journal of Applied Engineering Science, 2017, vol. 15, no. 3, pp. 381-386.

14. Zhou W., Tang L., Ma G., Liu X., Chen M. Mesoscopic simulation of the dynamic tensile behaviour of concrete based on a rate-dependent cohesive model. International Journal of Impact Engineering, 2016, vol. 95, pp. 165-175.

15. Li H.-Y., Teng J., Li Z.-H. An efficient platform HSNAS (GPU) for nonlinear static and dynamic analysis of reinforced concrete frames-II. Program verification and analysis. Zhendong yu Chongji, 2016, vol. 35, no. 14, pp. 54-60.

16. Chen X., Chen C., Xu L., Shao Y. Dynamic flexural strength of concrete under high strain rates. Magazine of Concrete Research, 2017, vol. 69, no. 3, pp. 109-119.

17. Geniev G.A. 0 vlyanii prodolzhitelnosti deystvya nagruzki na prochnost materiala [Effect of duration of load action on material strength]. Concrete and reinforced concrete, 1996, no. 4, pp. 19-22.

18. Plevkov V.S. Dinamicheskaya prochnost betona i armatury zhelezobetonykh konstruktsiy [Dynamic strength of concrete and rebar reinforced concrete structures]. Tomsk, TSUAB Publ., 1996. $64 \mathrm{p}$.

19. Bespayev A.A., Kuralov U.S., Altigenov U.B. Investigation of the work of bent ferro-concrete structures reinforced with fibroreinforced plastics under dynamic influences. Seysmostoykoye stroitelstvo. Bezopasnost sooruzheniy, 2015, no. 3, pp. 43-45. In Rus.

20. Bragov A.M., Konstantinov A.Yu., Lomunov A.K., Lamzin D.A. Investigation of mechanical properties of fine-grained concrete under dynamic loading. Privolzhskiy nauchny zhurnal, 2014, no. 4 (32), pp. 11-21. In Rus.

21. Tamrazyan A.G., Avetisyan L.A. Calculation of off-centered reinforced concrete elements for a short-term dynamic load. Stroitelstvo: nauka i obrazovanie, 2013, no. 4, pp. 2-6. In Rus.

22. Barbashev N.P. Calculation of the reinforced concrete arch in the ground on the effect of the dynamic load. Bulletin of MGSU, 2016, no. 1, pp. 35-43. In Rus.

23. Tamov M.A. Raschet zhelezobetonny izgibayemykh elementov, ar mirovannykh vysokoprochnymi stalyami, na dinamicheskie nagruzki [Calculation of reinforced concrete bending elements reinforced with high-strength steels, for dynamic loads]. Deposited manuscript, no. 3016 01.02.1982.

24. Tamrazyan A.G., Avetisyan L.A. Strength and load-bearing capacity of compressed reinforced concrete elements under dynamic loading under elevated temperatures. Promyshlennoe $i$ grazhdanskoe stroitelstvo, 2016, no. 7, pp. 56-60. In Rus.

25. Sembaev B.N., Grushevskiy K.E. Metody rascheta zhelezobetonnykh konstruktsiy na dinamicheskie nagruzki [Methods for calculating reinforced concrete structures for dynamic loads]. Upravlenie sotsialno-ekonomicheskimi sistemami: teoriya, metodologiya, praktika. Sbornik statey Mezhdunarodnoy nauchno-prakticheskoy konferentsii [Control of social and economic systems: theory, methodology, practice. Proc. of International scientific and practical conference]. Moscow, 2017. pp. 45-47. In Rus.

26. Bragov A.M., Konstantinov A.Yu., Petrov Yu.V., Smirnov I.V., Karihaloo B.L., Lamzin D.A., Lomunov A.K. Experimental-theoretical investigation of fiber reinforced concrete under dynamic loading. Fib Symposium TEL-AVIV 2013: Engineering a Concrete Future: Technology, Modeling and Construction. Tel-Aviv, 2013. pp. 633-636.

27. Berlinov M. Developing the phenomenological equations triaxial deformation of concrete under dynamic loads. MATEC Web of Conferences International Science Conference SPbWOSCE-2016 «SMART City». St-Petersburg, 2017. - P. 1-9.

28. Snozzi L., Molinari J.F., Gatuingt F. A meso-mechanical model for concrete under dynamic tensile and compressive loading. In- ternational Journal of Fracture, 2012, vol. 178, no. 1-2, pp. 179-194.

29. Long W.-J., Wei J.-J., Gu Y.-C., Xing F. Research on dynamic mechanical properties of alkali activated slag concrete under temperature-loads coupling effects. Construction and Building Materials, 2017, vol. 154, pp. 687-696.

30. Kotronis P., Mazars J., Davenne L. The equivalent reinforced concrete model for simulating the behavior of walls under dynamic shear loading. Engineering Fracture Mechanics, 2003, vol. 70, no. 7-8, pp. 1085-1097.

31. Rodevich V.V., Arzamastsev S.A. To evaluation of the strength of reinforced concrete bending elements under torsion from short-term dynamic loads. Vestnik of Tomsk State University of Architecture and Building, 2017, no. 2 (61), pp. 112-122. In Rus.

32. Kumpyak 0.G., Galyautdinov Z.R. Calculation of reinforced concrete slabs for short-time dynamic loads taking into account the real properties of materials. Concrete and reinforced concrete, 2007, no. 6, pp. 15-18. In Rus.

33. Utkin D.G. Deformation of bent steel-fiber-reinforced concrete elements with mixed reinforcement under short-time dynamic loading. Vestnik of Tomsk State University of Architecture and Building, 2015, № 5 (52), pp. 80-89. In Rus.

34. Utkin D.G., Grigoryev D.V., Zaytsev I.A. Determination of strength and deformation properties of steel-fiber-concrete in the case of static and short-term dynamic loading. Vestnik of Tomsk State University of Architecture and Building, 2016, no. 6 (59), pp. 139-149. In Rus.

35. Popov N.N., Rastorguev B.S. Voprosy rascheta $i$ konstruirovaniya spetsialnykh sooruzheniy [Issues of calculation and design of special structures]. Moscow, Stroyizdat Publ., 1980. 190 p.

36. Popov N.N., Rastorguyev B.S. Raschet zhelezobetonnykh konstruktsiy na deystvie kratkovremennykh dinamicheskikh nagru$z o k$ [Calculation of reinforced concrete structures for short-term dynamic loads]. Moscow, Stroyizdat Publ., 1964. 151 p.

37. Plevkov V.S., Radchenko A.V., Baldin I.V., Radchenko P.A., Goncharov M.E., Batuev S.P. Features of destruction of reinforced concrete structures under dynamic loading. Vestnik Tambovskogo Universiteta, 2013, vol. 18, Iss. 4, pp. 1578-1579. In Rus.

38. Belov N., Kopanitsa D., Yugov A., Kaparulin S., Plyaskin A., Kalichkina A., Ustinov A., Yugov N., Kopanitsa G. Calculation of reinforced-concrete frame strength under a simultaneous static cross section load and a column lateral impact. AIP Conference Proc. Advanced Materials in Technology and Construction. Tomsk, 2015. pp. 47-53.

39. Sarkisov D.Yu. Strength and deformability of reinforced concrete elements with oblique eccentric short-term dynamic compression, stretching and bending. Vestnik of Tomsk State University of Architecture and Building, 2008, no. 3, pp. 134-143. In Rus.

40. Plevkov V.S., Sarkisov D.Yu., Tigay 0.Yu. Investigation of reinforced concrete elements with oblique eccentric short-term dynamic compression, stretching and bending. Izvestiya Orlovskogo gosudarstvennogo tekhnicheskogo universiteta. Seriya: Stroitelstvo i transport, 2008, no 3-19, pp. 33-37. In Rus.

41. Odnokopylov G.I., Sarkisov D.Yu. Evaluation of breaking load parameters under shock wave loading for critical constructions of oil and gas sector facilities. Bulletin of the Tomsk Polytechnic University. Geo Assets Engineering, 2017, vol. 328, no. 3, pp. 85-95. In Rus.

42. Plevkov V.S., Sarkisov D.Yu., Baldin S.V. Analysis of the parameters of the oscillatory processes of the bearing frame of a production building. Building and reconstruction, 2017, no. 4 (72), pp. 47-56. In Rus.

43. Chiaia B., Kumpyak 0., Placidi L., Maksimov V.B. Experimental analysis and modeling of two-way reinforced concrete slabs over different kinds of yielding supports under short-term dynamic loading. Engineering Structures, 2015, no. 96, pp. 88-99. 
44. Mescheulov N., Kumpyak 0., Lyulevich Y. Deformability of oblique sections of rc beams on yielding supports under dynamic impact. AIP Conference Proc. Youth, Science, Solutions: Ideas and Prospects. Tomsk, 2017, pp. 1-8.

45. Galyautdinov Z.R. Deformation of reinforced concrete slabs on yielding supports under short-time dynamic loading. AIP Conference Proc. Youth, Science, Solutions: Ideas and Prospects. Tomsk, 2017. pp. 40-44.

46. Kumpyak 0.G., Mescheulov N.V. Numerical simulation of yielding supports in the shape of annular tubes under static and short-term dynamic loading. International Journal for Computational Civil and Structural Engineering, 2017, vol. 13, no. 4, pp. 103-113.

47. Kumpyak 0.G., Galyautdinov Z.R., Kokorin D.N. Strength of concrete structures under dynamic loading. AIP Conference Proc. Advanced Materials in Technology and Construction. Tomsk, 2016. pp. 59-68.

48. Kumpyak 0.G, Galyautdinov Z.R., Kokorin D.N. Prochnost i deformativnost zhelezobetonnykh konstruktsiy na podatlivykh oporakh pri kratkovremennom dinamicheskom nagruzhenii. Monografiya [Strength and deformability of reinforced concrete struc- tures on compliant supports under short-term dynamic loading. Monograph]. Tomsk, TSUAB Publ., 2016. 272 p.

49. Galyautdinov Z.R., Boglayeva M.M., Galyautdinov D.R., Ryumin E.V. Analiz dinamicheskogo deformirovaniya zhelezobetonnykh balok na podatlivykh oporakh [Analysis of the dynamic deformation of reinforced concrete beams on compliant supports]. Nauka i obrazovanie v zhizni sovremennogo obshchestva. Sbornik nauchnykh trudov po materialam mezhdunarodnoy nauchnoprakticheskoy konferentsii [Proc. of International scientific and practical conference. Science and education in modern society]. Tomsk, 2013. pp. 49-52.

50. Galyautdinov Z.R. Issledovanie raboty zhelezobetonnykh plit na podatlivykh oporakh pri kratkouremennom dinamicheskom nagruzhenii [Investigation of the work of reinforced concrete slabs on flexible bearings under short-term dynamic loading]. Bezopasnost stroitelnogo fonda Rossii. Problemy i resheniya. Materialy mezhdunarodnykh akademicheskikh chteniy [Safety of construction fund in Russia. Problems and solutions. Proc. of International academic readings]. Kursk, 2015. pp. 130-138.

Received: 7 November 2018.

\section{Information about the authors}

Georgy I. Odnokopylov, Dr. Sc., associate professor, National Research Tomsk Polytechnic University.

Dmitriy Yu. Sarkisov, Cand. Sc., associate professor, Tomsk State University of Architecture and Building.

Egor A. Butuzov, graduate student, Tomsk State University of Architecture and Building. 